УДК 582.912.46:547.814.5

\title{
АНТИОКСИДАНТНАЯ АКТИВНОСТЬ ВОДНЫХ ЭКСТРАКТОВ ПЛОДОВ КЛЮКВЫ ОБЫКНОВЕННОЙ (VACCINIUM OXYCOCCUS L.), ПРОИЗРАСТАЮЩЕЙ НА ТЕРРИТОРИИ РЕСПУБЛИКИ КОМИ
}

(ㄱ М.Ф. Борисенков ${ }^{1 *}$, Л.А. Бакутова ${ }^{1}$, А.В. Пещ

${ }^{1}$ Институт фризиологии Коми научного центра УрО РАН, ул. Первомайская, 50, Сыктывкар, 167982 (Россия), e-mail: borisenkov@physiol.komisc.ru

${ }^{2}$ Сыктывкарский государственный университет, Октябрьский проспект, 55, Сыктывкар, 167001 (Россия)

В результате исследований установлено, что АОА водного экстракта плодов клюквы зависит от содержания в нем фенольных веществ, поглощающих при 515 нм. Содержание АОА в клюкве не изменяется при хранении плодов при $-18^{\circ} \mathrm{C}$ в течение двух лет. Содержание АОА в плодах клюквы, собранной в различных регионах Республики Коми, не зависит от широты места ее произрастания.

Ключевые слова: клюква обыкновенная (Vaccinium oxycoccus L.), широта, антиоксидантная активность, общие фенолы, поглощение при 515 нм.

Принятые сокращения: АОА - антиоксидантная активность; $\mathrm{A}_{515}$ - поглощение образцов при $\lambda=515$ нм; ОФ содержание общих фенолов.

Работа выполнена при финансовой поддержке РФФИ (грант №12-04-00150-а).

\section{Введение}

В последнее время активно обсуждается роль антиоксидантов в защите растений от неблагоприятных климатических условий. В частности показано, что в растениях, подвергавшихся интенсивному облучению ультрафиолетом В, накапливается большое количество антиоксидантов фенольной природы, выполняющих роль ловушек свободных радикалов [1]. Облучение ультрафиолетом В и С каллусной культуры смолевки обыкновенной приводит к увеличению антиоксидантной активности и содержания фенолов в выделенных из нее пектинах. Причем наибольшим эффектом обладает ультрафиолет В [2]. Высказано предположение, что красные пигменты антоцианы, широко распространенные во всех видах растений, являются универсальным «химическим оружием», обеспечивающим защиту клеток растений от повреждающего действия климатических и других патогенных факторов окружающей среды [3].

Эта область физиологии растений тесно соприкасается с технологической проблемой, стоящей перед сельским хозяйством и пищевой промышленностью: подбором условий выращивания, переработки и хранения растительного сырья, обеспечивающих накопление и сохранение в продуктах питания полезных веществ, к которым относятся антиоксиданты. В плодах винограда, подвергшихся интенсивному ультрафиолетовому облучению, механическому повреждению, а также в сортах, устойчивых к грибковым заболеваниям, накап-

Борисенков Михаил Фёдорович - старший научный сотрудник отдела молекулярной иммунологии и биотехнологии, кандидат биологических наук, тел.: (8212) 24-10-01, e-mail: borisenkov@physiol.komisc.ru

Бакутова Лариса Александровна - старший лаборант, e-mail: larisa.bakutova@yandex.ru

Пещ Алёна Владимировна - выпускница кафедры химии, e-mail: lely-06@mail.ru ливается значительное количество антиоксидантов фенольной природы, в частности резвератрола [4]. Показано, что в корнеплодах моркови, подвергавшихся при хранении механическому повреждению и гипероксии, накапливается значительно больше фенольных антиоксидантов, чем в корнеплодах, хранившихся без воздействия стресса [5].

\footnotetext{
* Автор, с которым следует вести переписку.
} 
Плоды клюквы обыкновенной традиционно используются в пищу человеком. Они являются источником полезных веществ, обладающих бактерицидным и антиоксидантным действием [6]. Основная часть фенольных соединений клюквы представлена антоцианами [7], пигментами, придающими ягодам красный цвет. Антоцианы обладают выраженной антиоксидантной активностью как в условиях in vitro [8], так и in vivo [9]. Резвератрол - еще одно обнаруженное в клюкве вещество, относящееся к классу стильбенов, также является антиоксидантом [10]. Резвератрол обладает противовоспалительным [11], противораковым [12] и геропротекторным [13] действием на животных и человека. По содержанию резвератрола клюква не уступает отдельным сортам винограда [10].

Территория Республики Коми (РК) расположена в различных климатических зонах. Юг РК расположен на широте Санкт-Петербурга, тогда как ее север находится за полярным кругом. На территории РК произрастает один вид клюквы - клюква обыкновенная (Vaccinium oxycoccus L.). Можно предположить, что содержание антиоксидантов в плодах клюквы зависит от широты места произрастания.

Целью настоящего исследования явилось изучение антиоксидантной активности плодов клюквы, произрастающей в различных регионах РК.

\section{Экспериментальная часть}

Сбор и хранение образцов. Ягоды клюквы собирали в сентябре-октябре 2007-2010 гг. в десяти районах РК. Сведения о географических координатах и сроках сбора ягод представлены в таблице 1. Ягоды хранили до анализов в прохладном месте не более месяца или при $-18{ }^{\circ} \mathrm{C}$ до двух лет.

Подготовка проб для анализа. Навеску замороженных ягод растирали в фарфоровой ступке, добавляли равное по весу количество дистиллированной воды и полученный водный экстракт плодов клюквы фильтровали через бумажный фильтр (белая лента). Образцы хранили до анализов при $+4{ }^{\circ} \mathrm{C}$ не более суток.

Определение антиоксидантной активности. Антиоксидантную активность (АОА) водного экстракта плодов клюквы определяли методом кулонометрического титрования [14] с использованием кулонометра «Эксперт-006» фирмы «Эконикс-Эксперт» (Москва). Рабочий (анод, площадь $-2,3$ см$^{2}$ ) и вспомогательный (катод) электроды - стеклоуглеродные стержни диаметром 3 мм. Индикаторные - игольчатые платиновые электроды. Фоновый электролит - 0,2 М водный раствор бромистого калия в $0,1 \mathrm{M}$ серной кислоте. Рабочий ток - 5,27 мА, вспомогательный ток - 0,79 мА. Уровень измерения - 300 мВ, уровень уменьшения -500 мВ. Катодное и анодное отделения разделены полупроницаемой мембраной. В измерительную ячейку вносили 100 мл фонового электролита, погружали в электролит рабочий, вспомогательный и индикаторные электроды. Ячейку помещали на магнитную мешалку и при постоянном перемешивании электролита включали прибор. По встроенной программе прибор входит в рабочий режим. При этом в фоновом электролите образуется и поддерживается на одном уровне определенное количество активных форм брома. В анодную камеру измерительной ячейки вносили автоматической пипеткой аликвоту анализируемой пробы $\left(\mathrm{V}_{\mathrm{aл}}=100\right.$ мкл). Присутствующие в анализируемой пробе антиоксиданты реагировали с активными формами брома, в результате чего разность потенциалов в индикаторной системе начинала расти. При достижении «уровня уменьшения» анализатор начинал пропускать через электролит «основной ток» и запускал отсчет времени (титрование) до тех пор, пока разность потенциалов в индикаторной системе не достигала «уровня измерения». При этом восстанавливался исходный баланс электрогенерированных радикалов брома, нарушенный введением анализируемой пробы. Время титрования образца прямо пропорционально содержанию в нем антиоксидантов. АОА водного экстракта плодов клюквы выражали в единицах количества электричества $\mathrm{Q}$, затраченного на титрование единицы объема исследуемого вещества, которое рассчитывали по формуле: $\mathrm{Q}=(100 \times \mathrm{I} \times \mathrm{t}) / \mathrm{V}_{\text {ал }}$, где I - сила тока, $\mathrm{A} ; \mathrm{t}-$ время достижения конечной точки титрования, сек; $\mathrm{V}_{\text {ал }}$ - объем аликвоты, мл. Одновременно с анализируемыми образцами измеряли АОА стандартного образца, в качестве которого использовали $1 \%$-й раствор Тролокса (Sigma, США). АОА водного экстракта плодов клюквы выражали в мМоль-эквивалентах Тролокса на 100 мл раствора (мМ-экв Тролокса/100 мл). Каждый образец анализировали в 10 повторностях. В конечный результат анализов вносили поправку на разбавление.

Общее содержание фенольных соединений (ОФ) определяли с использованием реактива ФолинаЧиокальтеу (Ф-Ч) (Sigma, США) по методу, описанному в работе [15], с модификациями. Реакцию проводили в пластиковых пробирках Эппендорфа. Каждый образец анализировали в трех повторностях. К 30 мкл водного экстракта плодов клюквы добавляли 120 мкл реактива Ф-Ч и тщательно перемешивали. Через 
10 мин добавляли 50 мкл 0,2 М раствора бикарбоната натрия в $0,1 \mathrm{M}$ гидрокарбоната натрия. Содержимое пробирок тщательно перемешивали и инкубировали в течение 2 ч в темноте при комнатной температуре. По окончании инкубации смесь центрифугировали в течение 10 мин при 3000 об/мин, 120 мкл надосадочной жидкости переносили в лунки планшета и измеряли оптическую плотность растворов на планшетном спектрофотометре PowerWave 200 ${ }^{\mathrm{TM}}$ (Bio-Tek Instruments, США) при длине волны 765 нм. Общее содержание фенольных соединений в водном экстракте плодов клюквы определяли по калибровочному графику, построенному для феруловой кислоты (ФК, транс-4-гидрокси-3-метоксикоричная кислота) (Sigma, CША) (1-60 мкг ФК на лунку), и выражали в мг-эквивалентах ФК/мл раствора. В конечный результат анализов вносили поправку на разбавление.

Измерение оптической плотности водного экстракта плодов клюквы в области спектра с максимальным поглощением. Для измерения оптической плотности образцов использовали планшетный спектрофотометр. Используя один образец водного экстракта плодов клюквы, измерили спектр поглощения в видимой области света. Определили, что максимум поглощения водного экстракта плодов клюквы находится при 515 нм (рис. 1). В дальнейшем определили оптическую плотность всех анализируемых образцов водных экстрактов плодов клюквы при этой длине волны $\left(\mathrm{A}_{515}\right)$. Каждый образец анализировали в пяти повторностях. В конечный результат анализов вносили поправку на разбавление.

Обработка результатов. Результаты измерений представляли как среднее \pm стандартное отклонение. Для статистической обработки полученных результатов использовали критерий Стьюдента, корреляционный и регрессионный анализ.

Таблица 1. Сведения о месте и сроках сбора ягод

\begin{tabular}{c|l|c|c|c|c}
\hline \multirow{2}{*}{$№$} & \multicolumn{1}{|c|}{ Район } & \multicolumn{2}{|c|}{ Координаты } & \multicolumn{2}{|c}{ Сезон сбора ягод } \\
\cline { 3 - 6 } & & широта, град. с.ш. & долгота, град. в.д. & Месяц & Год \\
\hline 1 & с. Лойма & 60,5 & 48,9 & 9 & 2010 \\
2 & п. Красный Затон & 61,7 & 51,0 & 9 & 2008 \\
3 & с. Корткерос & 61,8 & 51,6 & 10 & 2007 \\
4 & с. Усть-Пожег & 62,0 & 50,2 & 9 & 2010 \\
5 & г. Микунь & 62,3 & 50,1 & 9 & 2008 \\
6 & с. Княж-Погост & 62,6 & 50,9 & 9 & 2010 \\
7 & д. Гам & 65,0 & 53,8 & 9 & 2010 \\
8 & г. Печора & 65,1 & 57,3 & 10 & 2010 \\
9 & с. Ижма & 65,3 & 53,4 & 9 & 2010 \\
10 & г. Инта & 66,0 & 60,2 & 9 \\
\hline
\end{tabular}

Рис. 1. Поглощение водных экстрактов плодов клюквы в видимой области спектра

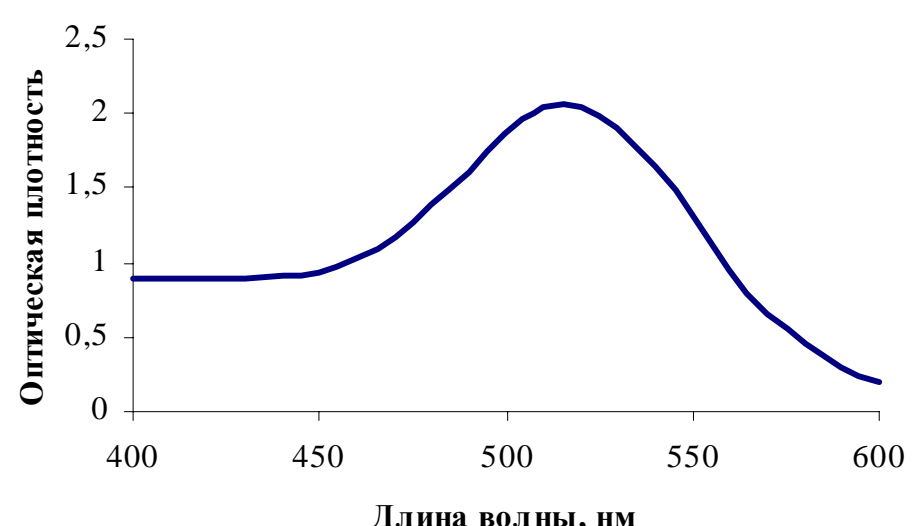

Длина волны, нм

\section{Результаты и их обсуждение}

Корреляция между содержанием фенольных соединений и АОА водных экстрактов плодов клюквы. Отмечена прямая зависимость между тремя изученными показателями: максимальные значения АОА, ОФ и $\mathrm{A}_{515}$ наблюдаются в пробе № 2, а минимальные - в пробе № $1^{1}$. Регрессионный анализ выявил прямую зависимость между АОА и ОФ, АОА и $\mathrm{A}_{515}$ и между $\mathrm{A}_{515}$ и ОФ (рис. 2). Высокие значения коэффициентов детерминации $\left(\mathrm{R}^{2}\right)$ свидетельствуют о том, что от 73 до $84 \%$ вариабельности показателей объясняет линейная регрессия, уравнения которых приведены на графиках. 
Максимальный коэффициент детерминации отмечен при анализе связи между $\mathrm{A}_{515}$ и ОФ. Эту зависимость можно интерпретировать следующим образом: фенольные соединения в водных экстрактах плодов клюквы в основном представлены веществами, поглощающими при 515 нм. Этот вывод согласуется с результатами предыдущих исследований, свидетельствующих о том, что основным классом фенольных соединений клюквы являются гликозиды антоцианов [7]. В кислой среде максимум поглощения гликозидов антоцианов находится вблизи 515 нм [16].

Наличие прямой зависимости меду содержанием ОФ и АОА (рис. 3) свидетельствует о том, что антиоксидантная активность водных экстрактов плодов клюквы в основном обусловлена содержащимися в них фенольными соединениями, а принимая во внимание наличие положительной связи между АОА и ОП $_{515}$, можно утверждать, что АОА водных экстрактов плодов клюквы на $73 \%$ зависит от содержащихся в них гликозидов антоцианов. Эти выводы в целом согласуются с данными литературы. Ранее было показано наличие положительной корреляции между содержанием ОФ и АОА водных экстрактов плодов клюквы, оцененной методом ORAC [17]. Аналогичный результат был получен в работе [18] при исследовании содержания ОФ и АОА в соке ягод семейства Vaccinium. Отмечена также прямая корреляционная связь между АОА клюквы в условиях in vitro и содержанием антоцианов [8]. Однако не во всех случаях ранее была выявлена положительная корреляция между АОА и ОФ сока клюквы. Такой связи не удалось обнаружить при использовании для оценки АОА стабильного радикала ДФПГ [19]. По-видимому, негативный результат в последнем случае обусловлен использованием неадекватного метода для оценки АОА сока клюквы. Метод с использованием стабильного радикала ДФПГ дает более надежные результаты при оценке АОА жирорастворимых соединений [20]. Между тем известно, что АО сока клюквы в основном представлены водорастворимыми гликозидами цианидина [7].

Влияние места сбора и условий хранения ягод на АОА водных экстрактов плодов клюквы. Отмечено значительное варьирование показателя АОА водных экстрактов плодов клюквы в различных образцах. Разница между минимальным и максимальным значениями составила 2,6 раза (табл. 2).

Не отмечено зависимости АОА водных экстрактов плодов клюквы от широты места произрастания растения (рис. 3). Водные экстракты ягод, собранных на севере РК, обладают умеренной АОА, тогда как среди образцов, собранных на юге РК, встречаются пробы с минимальными (проба № $1^{1}$ ) и максимальными (пробы № 2 и 3) значениями. Пробы № $1^{1}$ и $1^{2}$, собранные примерно в одно время на разных болотах вблизи села Лойма, отличаются по показателям АОА, ОФ и $\mathrm{A}_{515}$ в два раза (табл. 2). По-видимому, на содержание АОА в водных экстрактах плодов клюквы в большей степени влияют локальные условия произрастания. В работе [7] показано, что воздействие дневного света в период сбора урожая оказывает наиболее сильное влияние на содержание антоцианов в ягодах клюквы.
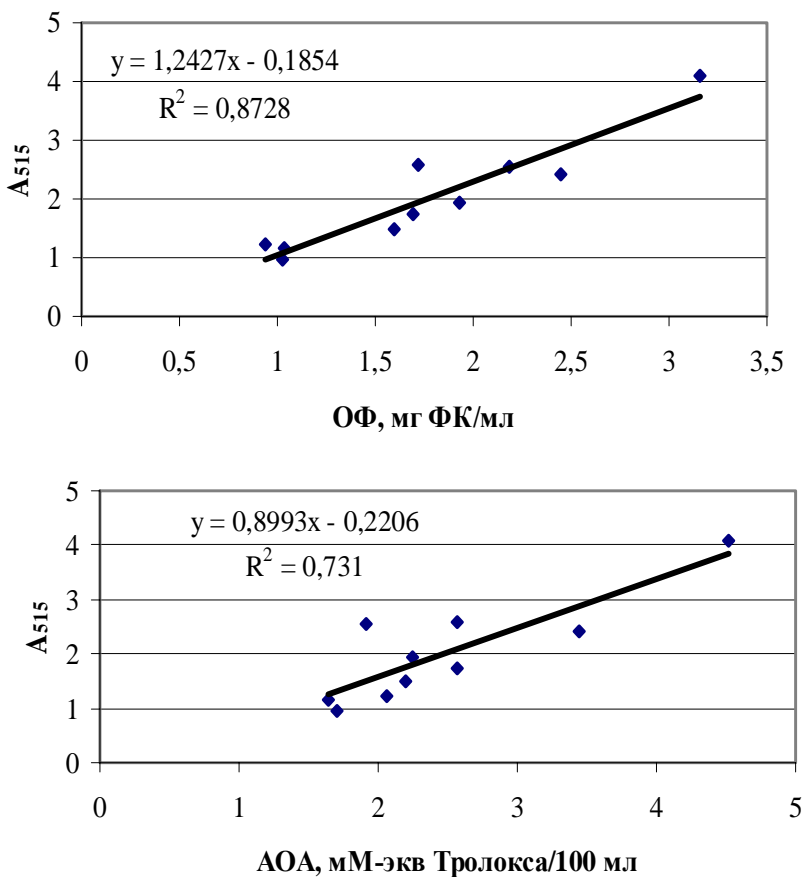

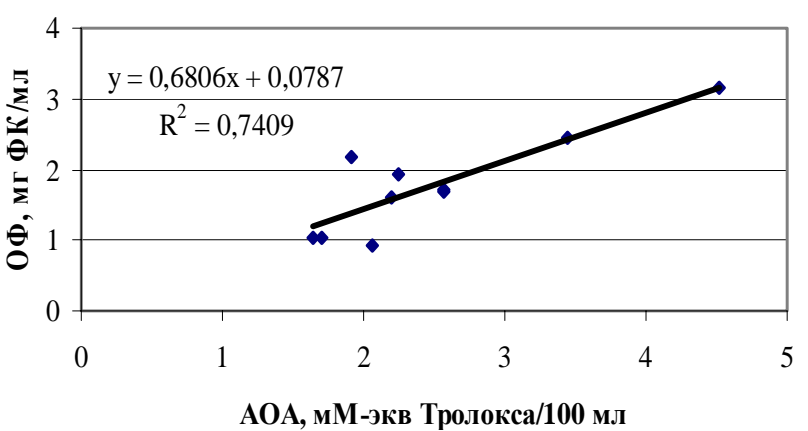

Рис. 2. Регрессионный анализ связи между анализируемыми показателями: $\mathrm{A}_{515}$ - поглощение образцов при $\lambda=515$ нм; АОА - антиоксидантная активность; ОФ - содержание общих фенолов; на графиках точками отмечены средние значения показателей, сплошной линией - регрессия, уравнения линейной регрессии и коэффициенты детерминации $\left(\mathrm{R}^{2}\right)$ 
Таблица 2. Сводная таблица результатов измерения АОА, общих фенолов и поглощения при 515 нм водных экстрактов плодов клюквы

\begin{tabular}{c|c|c|c}
\hline № & АОА, мМ-экв Тролокса/100 мл & ОФ, мГ ФК/мл & $\mathrm{A}_{515}$ \\
\hline $1^{1}$ & $1,71 \pm 0,15$ & $2,48 \pm 0,02$ & $0,97 \pm 0,05$ \\
$1^{2}$ & $3,45 \pm 0,10$ & $5,92 \pm 0,24$ & $2,41 \pm 0,18$ \\
2 & $4,52 \pm 0,20$ & $7,65 \pm 0,89$ & $4,09 \pm 0,06$ \\
3 & $4,41 \pm 0,12$ & $\ldots$ & $\ldots$ \\
4 & $2,56 \pm 0,13$ & $4,11 \pm 0,14$ & $1,74 \pm 0,07$ \\
$5^{3}$ & $1,83 \pm 0,24$ & $\ldots$ & $\ldots$ \\
$5^{3}$ & $1,64 \pm 0,12$ & $2,50 \pm 0,16$ & $2,17 \pm 0,03$ \\
6 & $1,91 \pm 0,29$ & $5,28 \pm 0,25$ & $2,57 \pm 0,11$ \\
7 & $2,56 \pm 0,13$ & $4,17 \pm 0,14$ & $1,94 \pm 0,05$ \\
8 & $2,25 \pm 0,14$ & $4,67 \pm 0,26$ & $1,24 \pm 0,03$ \\
9 & $2,06 \pm 0,09$ & $2,27 \pm 0,07$ & $1,49 \pm 0,01$ \\
\hline
\end{tabular}

Примечания: номерами 1-10 отмечены районы произрастания клюквы, как на рисунке 1 и в таблице $1 ; 1^{1,2}-$ образцы собраны в районе с. Лойма на двух разных болотах; $5^{3}$ - АОА образца 5 проанализировали дважды, сразу после сбора ягод и через два года хранения ягод при $-18{ }^{\circ} \mathrm{C} ; \cdots-$ измерения не проводились; ОФ - содержание общих фенолов; ФК - феруловая кислота; $\mathrm{A}_{515}$ - поглощение водных экстрактов плодов клюквы при $\lambda=515$ нм.

Рис. 3. Анализ влияния широты места произрастания клюквы на содержание АО в ягодах. На графиках точками отмечены средние значения показателей, цифрами отмечены номера образцов, как в таблице 1 и на рисунке 1 , сплошной линией - регрессия, уравнения линейной регрессии и коэффициенты детерминации $\left(\mathrm{R}^{2}\right)$.

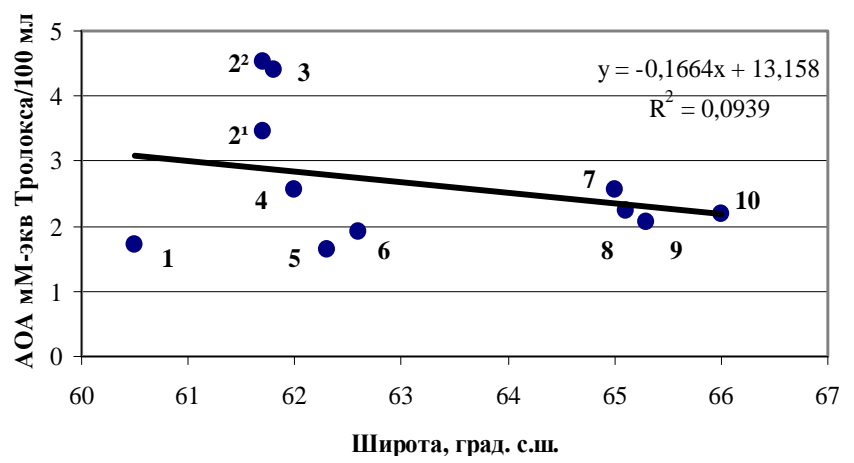
AOA - антиоксидантная активность

АОА водных экстрактов плодов клюквы не изменяется при хранении ягод в течение двух лет в замороженном виде (табл. 2). Этот вывод согласуется с данными, приведенными в работе [21]. Авторами показано, что антоцианы голубики сохраняются в наибольшей степени при хранении ягод в течение трех месяцев в замороженном виде. Анализ содержания общих фенолов в продуктах, приготовленных из клюквы различными способами (замороженный сок, высушенный сок, 100\%-й сок, 27\%-й сок, пюре, желе), установил, что в замороженном соке сохраняется максимальное их количество [22].

\section{Выводы}

1. Антиоксидантная активность водных экстрактов плодов клюквы в основном обусловлена содержанием в нем фенольных соединений с максимумом поглощения при 515 нм в кислой среде и практически не изменяется при хранении ягод при $-18^{\circ} \mathrm{C}$ в течение двух лет.

2. Наличие тесной корреляционной связи между изученными показателями позволяет предложить простой и эффективный тест для экспресс-анализа антиоксидантной активности водных экстрактов плодов клюквы по поглощению при 515 нм.

3. Содержание антиоксидантов в водных экстрактах плодов клюквы не зависит от широты места ее произрастания.

\section{Список литературы}

1. Lavola A. Accumulation of flavonoids and related compounds in birch induced by UV-B irradiance // Tree Physiol. 1998. Vol. 18, №1. Pp. 53-58.

2. Гюнтер Е.А., Борисенков М.Ф., Оводов Ю.С. Действие ультрафиолета на строение и антиоксидантную активность силенана каллуса смолевки обыкновенной // Прикладная биохимия и микробиология. 2009. Т. 45, №4. C. $470-475$.

3. Gould K.S. Nature's swiss army knife: The diverse protective roles of anthocyanins in leaves // J. Biomed. Biotechnol. 2004. Vol. 5. Pp. 314-320. 
4. Soleas G.J., Diamandis E.P., Goldberg D.M. The world of resveratrol // Adv. Exp. Med. Biol. 2001. Vol. 492. Pp. 159-182.

5. Jacobo-Velzquez D.A., Martnez-Hernandez G.B., Rodrguez S.C., Cao C.-M., Cisneros-Zevallos L. Plants as biofactories: Physiological role of reactive oxygen species on the accumulation of phenolic antioxidants in carrot tissue under wounding and hyperoxia stress // J. Agric. Food Chem. 2011. Vol. 59, N12. Pp. 6583-6593.

6. McKay D.L., Blumberg J.B. Cranberries (Vaccinium macrocarpon) and Cardiovascular Disease Risk Factors // Nutr. Rev. 2007. Vol. 65, N11. Pp. 490-502.

7. Zhou Y., Singh B.R. Effect of light on anthocyanin levels in submerged, harvested cranberry fruit // J. Biomed. Biotechnol. 2004. Vol. 2004, N5. Pp. 259-263.

8. Wu X., Beecher G.R., Holden J.M., Haytowitz D.B., Gebhardt S.E., Prior R.L. Lipophilic and hydrophilic antioxidant capacities of common foods in the United States // J. Agric. Food Chem. 2004. Vol. 52, N12. Pp. 4026-4037.

9. Bitsch R., Netzel M., Frank T., Strass G., Bitsch I. Bioavailability and biokinetics of anthocyanins from red grape juice and red wine // J. Biomed. Biotechnol. 2004. Vol. 2004, N5. Pp. 293-298.

10. Wang Y., Catana F., Yang Y., Roderick R., van Breemen R.B. An LC-MS Method for analyzing total resveratrol in grape juice, cranberry juice, and in wine // J. Agric. Food Chem. 2002. Vol. 50, N3. Pp. 431-435.

11. Udenigwe CC, Ramprasath VR, Aluko RE, Jones PJ. Potential of resveratrol in anticancer and anti-inflammatory therapy // Nutr. Rev. 2008. Vol. 66, N8. Pp. 445-454.

12. Aggarwal B.B., Bhardwaj A., Aggarwal R.S., Seeram N.P., Shishodia S., Takada Y. Role of resveratrol in prevention and therapy of cancer: preclinical and clinical studies // Anticancer Res. 2004. Vol. 24, N5A. Pp. 2783-2840.

13. Wood J.G., Rogina B., Lavu S., Howitz K., Helfand S.L., Tatar M., Sinclair D. Sirtuin activators mimic caloric restriction and delay ageing in metazoans // Nature. 2004. Vol. 430, N7000. Pp. 686-689.

14. Заявка на патент 2003132741/13 РФ. Способ определения интегральной антиоксидантной емкости продуктов питания и напитков / Абдуллин И.Ф., Чернышева Н.Н., Зиятдинова Г.К., Лапин А.А. // БИ. 2005. № 12.

15. Singleton V.L., Rossi J.A. Colorimetry of total phenolics with phosphomolybdic-phosphotungstic acid reagents // Am. J. Enol. Vitic. 1965. Vol. 16, N3. Pp. 144-158.

16. Cabrita L., Fossen T., Andersen Ø.M. Colour and stability of the six common anthocyanidin 3-glucosides in aqueous solutions // Food Chem. 2000. Vol. 68. Pp. 101-107.

17. Wang S.Y., Stretch A.W. Antioxidant capacity in cranberry is influenced by cultivar and storage temperature // J. Agric. Food Chem. 2001. Vol. 49, N2. Pp. 969-974.

18. Ehala S., Vaher M., Kaljurand M. Characterization of phenolic profiles of Northern European berries by capillary electrophoresis and determination of their antioxidant activity // J. Agric. Food Chem. 2005. Vol. 53, N16. Pp. 6484-6490.

19. Viskelis P., Rubinskiene M., Jasutiene I., Sarkinas A., Daubaras R., Cesoinene L. Anthocyanins, antioxidative, and antimicrobial properties of american cranberry (Vaccinium macrocarpon Ait.) and their press cakes // J. Food Sci. 2009. Vol. 74, N2. Pp. 157-161.

20. Чукичева И.Ю., Буравлев Е.В., Федорова И.В., Борисенков М.Ф., Кучин А.В. Антиоксидантные свойства терпенофенолов // Изв. РАН. Сер. хим. 2010. №12. С. 2220-2224.

21. Lohachoompol V., Srzednicki G., Craske J. The change of total anthocyanins in blueberries and their antioxidant effect after drying and freezing // J. Biomed. Biotechnol. 2004. Vol. 2004, №5. Pp. 248-252.

22. Vinson J.A., Bose P., Proch J., Al Kharrat H., Samman N. Cranberries and cranberry products: Powerful in vitro, ex vivo, and in vivo sources of antioxidants // J. Agric. Food Chem. 2008. Vol. 56, N14. Pp. 5884-5891.

Поступило в редакцию 26 июня 2012 г. 
Borisenkov M.F. ${ }^{{ }^{*},}$, Bakutova L.A. ${ }^{l}$, Peshch A.V. ${ }^{2}$ ANTIOXIDANT ACTIVITY OF WATER EXTRACTS CRANBERRY FRUIT VACCINIUM OXYCOCCUS L., GROWING ON THE REPUBLIC OF KOMI

${ }^{I}$ Institute of Physiology, Komi Scientific Center, RAS, Pervomaiskaia st., 50, Syktyvkar, 167982 (Russia),

e-mail: borisenkov@physiol.komisc.ru

${ }^{2}$ Syktyvkar State University, Oktiabr'skii ave., 55, Syktyvkar, 167001 (Russia)

As a result of investigations it was found that the antioxidant activity of aqueous extract of cranberry fruit is mainly determined by quantities of phenolic compounds, absorbing at $515 \mathrm{~nm}$. The content of antioxidants in the cranberries does not change during storage of fruits at $-18{ }^{\circ} \mathrm{C}$ for two years. The AOA of cranberry, collected in different regions of the Komi Republic, does not depend on the latitude of its habitat.

Keywords: cranberry (Vaccinium oxycoccus L.), latitude, antioxidant activity, total phenolics, absorbance at $515 \mathrm{~nm}$.

\section{References}

1. Lavola A. Tree Physiol. 1998, vol. 18, no. 1, pp. 53-58.

2. Giunter E.A., Borisenkov M.F., Ovodov Iu.S. Prikladnaia biokhimiia i mikrobiologiia, 2009, vol. 45, no. 4, pp. 470-475. (in Russ.).

3. Gould K.S. J. Biomed. Biotechnol., 2004, vol. 5, pp. 314-320.

4. Soleas G.J., Diamandis E.P., Goldberg D.M. Adv. Exp. Med. Biol., 2001, vol. 492, pp. 159-182.

5. Jacobo-Velzquez D.A., Martnez-Hernandez G.B., Rodrguez S.C., Cao C.-M., Cisneros-Zevallos L. J. Agric. Food Chem., 2011, vol. 59, no. 12, pp. 6583-6593.

6. McKay D.L., Blumberg J.B. Nutr. Rev., 2007, vol. 65, no. 11, pp. 490-502.

7. Zhou Y., Singh B.R. J. Biomed. Biotechnol., 2004, vol. 2004, no. 5, pp. 259-263.

8. Wu X., Beecher G.R., Holden J.M., Haytowitz D.B., Gebhardt S.E., Prior R.L. J. Agric. Food Chem., 2004, vol. 52, no. 12 , pp. 4026-4037.

9. Bitsch R., Netzel M., Frank T., Strass G., Bitsch I. J. Biomed. Biotechnol., 2004, vol. 2004, no. 5, pp. 293-298.

10. Wang Y., Catana F., Yang Y., Roderick R., van Breemen R.B. J. Agric. Food Chem., 2002, vol. 50, no. 3, pp. 431-435.

11. Udenigwe CC, Ramprasath VR, Aluko RE, Jones PJ. Nutr. Rev., 2008, vol. 66, no. 8, pp. 445-454.

12. Aggarwal B.B., Bhardwaj A., Aggarwal R.S., Seeram N.P., Shishodia S., Takada Y. Anticancer Res., 2004, vol. 24, no. 5A, pp. 2783-2840.

13. Wood J.G., Rogina B., Lavu S., Howitz K., Helfand S.L., Tatar M., Sinclair D. Nature, 2004, vol. 430, no. 7000, pp. 686-689.

14. Application for a patent 2003132741/13 (RU). 2005. (in Russ.).

15. Singleton V.L., Rossi J.A. Am. J. Enol. Vitic., 1965, vol. 16, no. 3, pp. 144-158.

16. Cabrita L., Fossen T., Andersen Ø.M. Food Chem., 2000, vol. 68, pp. 101-107.

17. Wang S.Y., Stretch A.W. J. Agric. Food Chem., 2001, vol. 49, no. 2, pp. 969-974.

18. Ehala S., Vaher M., Kaljurand M. J. Agric. Food Chem., 2005, vol. 53, no. 16, pp. 6484-6490.

19. Viskelis P., Rubinskiene M., Jasutiene I., Sarkinas A., Daubaras R., Cesoinene L. J. Food Sci., 2009, vol. 74, no. 2, pp. 157-161.

20. Chukicheva I.Iu., Buravlev E.V., Fedorova I.V., Borisenkov M.F., Kuchin A.V. Izvestiia Akademii nauk. Seriia khimicheskaia, 2010, no. 12, pp. 2220-2224. (in Russ.).

21. Lohachoompol V., Srzednicki G., Craske J. J. Biomed. Biotechnol., 2004, vol. 2004, №5, pp. 248-252.

22. Vinson J.A., Bose P., Proch J., Al Kharrat H., Samman N. J. Agric. Food Chem., 2008, vol. 56, no. 14, pp. 5884-5891.

Received June 26, 2012

\footnotetext{
* Corresponding author.
} 
